\title{
Pronunciamiento
}

\section{La violencia no se combate con más violencia. Un llamado a la sensatez}

\section{Universidad Centroamericana "José Simeón Cañas"}

El gobierno ha concluido al fin que es necesario actuar para combatir el auge de la delincuencia. Mucho tardó en arribar a esta conclusión, a la cual el pueblo salvadoreño llegó hace muchísimo tiempo. Nuestras encuestas de opinión pública señalan, desde 1992, la delincuencia como la segunda gran preocupación de los salvadoreños $y$, desde 1994, como la primera, representando incluso un porcentaje mayor que la guerra en sus peores momentos. La presión y la amenaza por parte de un grupo de empresarios fue necesaria para convencer al gobierno de que debía hacer algo importante al respecto.

Recogiendo el clamor popular, confirmado por el análisis, la UCA ha venido advirtiendo sobre este grave problema nacional desde 1992. Por lo tanto, reconocemos su existencia y su gravedad, pero no estamos de acuerdo con el tratamiento que se le está dando, no sólo porque las medidas propuestas hasta ahora no son adecuadas, sino porque además representan un peligro real que podría llevar a una nueva guerra, esta vez, difusa e informal.

\section{La complejidad del problema}

En El Salvador se asesina con mucha facilidad y frecuencia. El registro de la Fiscalía General de la República muestra 7,877 homicidios dolosos en 1995, lo cual significa un promedio de 21 asesinatos diarios. El promedio anual de los dos últimos años, según esta fuente, asciende a 8,506 muertes violentas, lo cual significa que el índice de 
estas muertes ha aumentado el 36 por ciento en relación a los doce años de guerra, en los cuales murieron 75 mil personas (un promedio anual de 6,250). Estos datos ponen en entredicho las afirmaciones de quienes hablan de una transición de postguerra exitosa.

El sensacionalismo de la prensa asocia con facilidad homicidios y delincuencia, dando pie para justificar medidas extremadamente punitivas. La violencia no es sólo un problema de delincuencia. Evidentemente, la mayoría de las muertes violentas desde 1992 se debe a la incidencia de la criminalidad, pero detrás de cada asesinato no está únicamente el deseo perverso del criminal, sino que, además, intervienen una serie de aspectos, desde los culturales hasta los relacionados con la impunidad y la disponibilidad de armas de fuego, pasando por la herencia social de la guerra. Por lo tanto, en cada acto violento hay que considerar el contexto psicosocial de la conducta, la permisividad social, el armamento del que dispone la sociedad y un aparato de seguridad $y$ un sistema judicial deficientes.

En cada acto violento hay que considerar el contexto psicosocial de la conducta, la permisividad social, el armamento del que dispone la sociedad y un aparato de seguridad y un sistema judicial deficientes.

En el ámbito psicosocial de la conducta se inscriben ciertas pautas de relación aprendidas durante la guerra: los conflictos e incluso las relaciones personales se conducen agresivamente. La persistencia de esas pautas permite hablar de una cultura de la violencia, la cual está estrechamente relacionada con la forma como el Estado cumple sus funciones y legitima el uso de la fuerza y la violencia para conseguir sus objetivos, los cuales justifica contradictoriamente, alegando promover el derecho. El Estado promueve la cultura de la violencia en la medida en que responde a las demandas sociales de manera agresiva.

Existen normas y valores aprendidos en la guerra y reforzados en la postguerra que se han llegado a considerar aceptables, convirtiendo lo anómalo y lo ilícito e incluso lo ilegal en la regla. Así, valores como el autoritarismo y la intolerancia no sólo permean la actividad política, sino que también determinan las relaciones cotidianas entre los salvadoreños y legitiman el recurso a la agresión en cualquier circunstancia. 
El elevado índice de violencia es posible, en buena medida, por la circulación libre de armas, las cuales se negocian lícita e ilícitamente. La guerra dejó una cantidad considerable de armas de fuego fuera de control; se trata de un arsenal que la autoridad no ha podido controlar aún. Sin embargo, a estas alturas de la postguerra, el problema ya no se limita a las armas que dejó el conflicto, sino a que cualquiera puede obtener un arma de fuego fácilmente. Alegando que es necesario que la ciudadanía se proteja de los ataques de la delincuencia, se permite y estimula la adquisición de armas de fuego y así se entra en una espiral, en la cual ciudadanos y delincuentes se arman cada vez más y mejor, y donde cada uno debe ser más astuto que el otro para sobrevivir. Así, lo único que se asegura es la propia muerte. No es exagerado afirmar, por tanto, que la sociedad se encuentra en armas contra sí misma.

La violencia está directamente relacionada con las deficiencias del aparato de seguridad y del sistema judicial, en particular con la tolerancia de la impunidad. En la medida en que ambos sean vulnerables a la corrupción, la impunidad seguirá estimulando la violencia. Por lo tanto, no se trata de imponer leyes más drásticas, sino de conseguir que se investigue y se administre justicia.

La globalización de las relaciones económicas ha desquiciado las estructuras de la sociedad. El mercado irrestricto, el consumo desenfrenado y el individualismo a ultranza han anulado la influencia de las estructuras sociales tradicionales de la familia, la comunidad, las iglesias, las asociaciones e incluso el mismo Estado. La riqueza y la seguridad derivada de ella hacen a los individuos menos dependientes

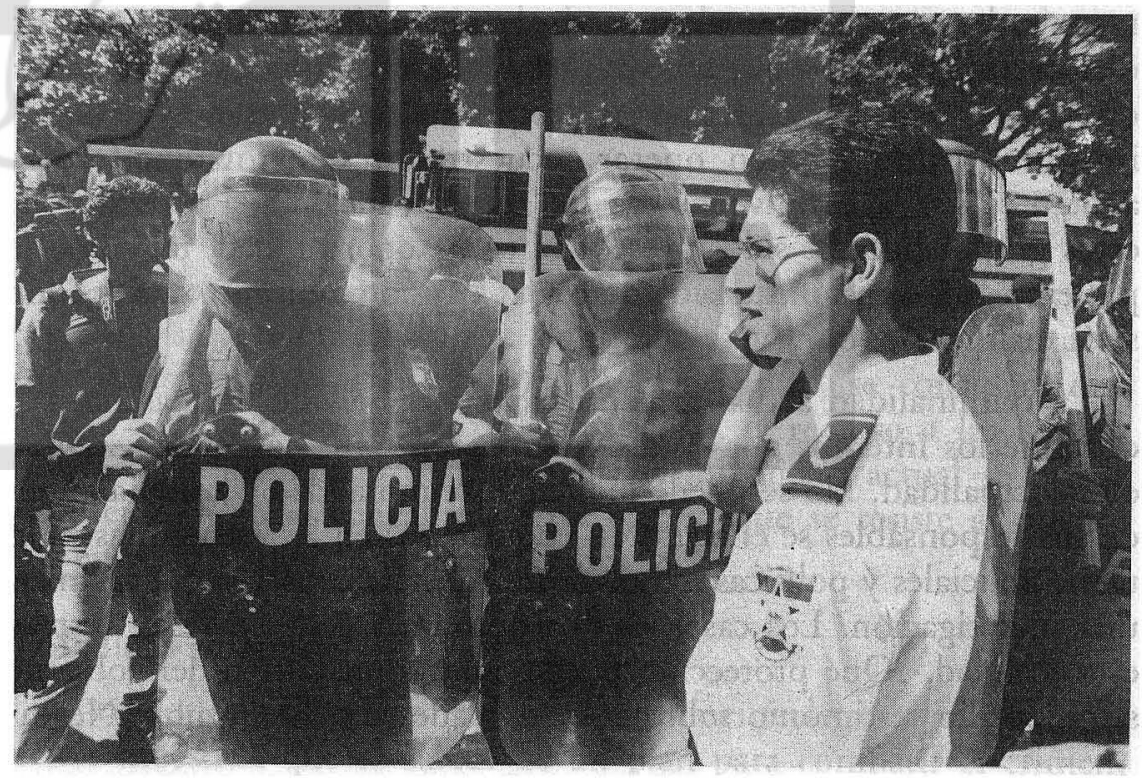


y permeables a las costumbres, principios y normas. Lo que se ha ganado en libertad, se ha perdido en principios, valores y relaciones sociales. La globalización y su idolatrización del mercado han desatado unas fuerzas que se han vuelto contra sus promotores, pues la violencia no hace distinción de clases sociales.

La violencia está relacionada con el desempleo, la pobreza y la frustración, pero también con la sanción social que considera la ganancia individual más importante que la equidad, promoviendo así la violación de la ley por el afán de acumular riquezas, poder, prestigio y satisfacción personal. Esta mentalidad siempre encuentra la forma para condonar o ignorar el crimen. Por eso, éste no sólo refleja los valores criminales, sino también los de la sociedad que los permite y acepta (ver $E C A, 1995,563$, p. 797).

\section{Los costos del olvido}

El discurso oficial exige mano dura contra el delito, pensando equivocadamente que éste desaparece con leyes más estrictas, fusiles de asalto y manos libres para usar la fuerza. Leyes más drásticas no resolverán el problema, porque éste no es primordialmente de orden legal, sino de falta de investigación y administración de justicia. Los fusiles de asalto sólo aumentarán la violencia, mientras que el uso amplio de la fuerza abre la puerta a mayores abusos contra el debido proceso y a nuevas violaciones de los derechos humanos.

No es la ley la que protege al delincuente, sino los funcionarios corruptos que toleran y promueven la impunidad así como también la permisividad de la sociedad. Muchos de quienes ahora protestan tan airadamente contra el auge de la violencia se opusieron o no dieron importancia a que se investigara a los escuadrones de la muerte que se han convertido en bandas de criminales organizados. Es difícil imaginar cómo pueden operar secuestradores, extorsionadores y asaltantes sin la connivencia de las autordidades. Si la actividad de estos grupos hubiese sido investigada en su oportunidad, tal como lo pidieron la Comisión de la Verdad y el Grupo Conjunto, la situación sería distinta.

La criminalidad actual es consecuencia del olvido del pasado. No obstante los intentos por evadirlo, el pasado sigue cobrando víctimas en la actualidad. No se puede reducir la criminalidad cuando algunos de sus responsables se encuentran enquistados en las estructuras militares, policiales y políticas, tal como se constata cada vez que se inicia una investigación. Los casos de "La Sombra Negra" y Veliz ilustran esta realidad. ¿Qué protección puede esperar un testigo del gobierno si quien dio testimonio sobre las actividades de "La Sombra Negra" 
fue reprendida por la misma dirección de la policía por implicar a altos funcionarios y además perdió su trabajo?

Calcularon mal al pensar que tomando la justicia en sus manos acabarían con el enemigo comunista y vivirían en paz. Ahora enfrentan a otro enemigo más virulento. Los escuadrones de la muerte que surgieron durante la guerra se han vuelto, en primer lugar, contra sus creadores $y$, en segundo lugar, contra la sociedad en su conjunto, en la postguerra. Los crímenes del pasado todavía no se han podido aclarar

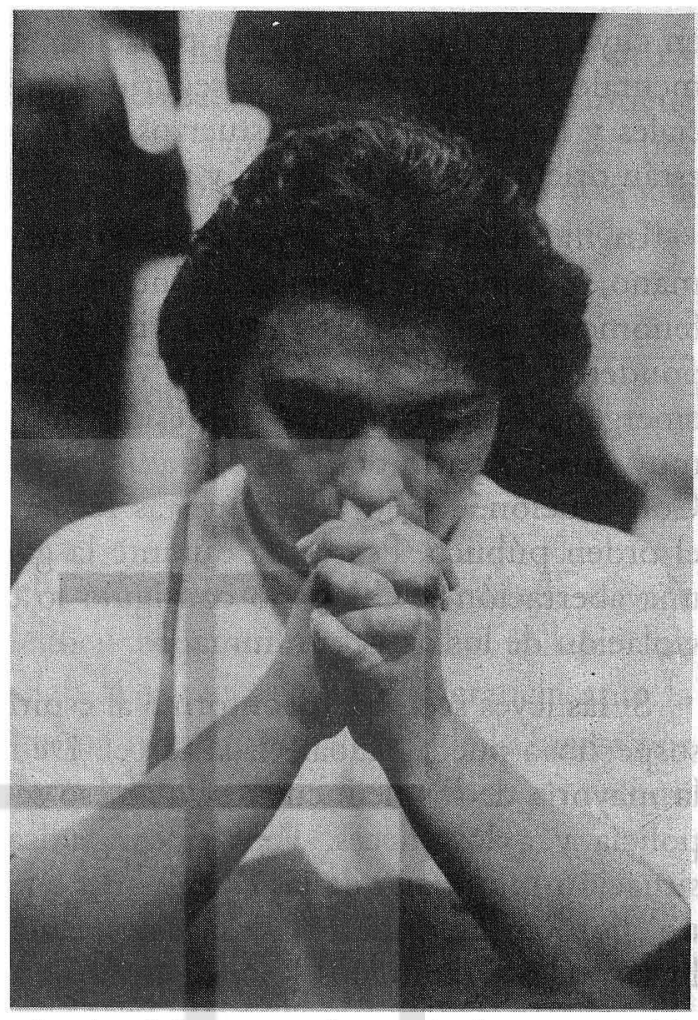
$y$, por lo tanto, no se ha hecho justicia, pero el pasado ha convertido a sus responsables, por comisión u omisión, en la víctima principal del secuestro, la extorsión y el asalto.

La criminalidad actual se puede interpretar

como la venganza de un pasado que se resiste al olvido.

El pasado aún no ha sido superado, pues los viejos dinamismos represivos siguen operando. Se continúa pensando que cualquiera puede hacer uso de la fuerza. Al igual que antes, se considera que cuando el Estado no garantiza la seguridad, el recurso a las bandas armadas está justificado. Así, pues, la criminalidad actual se puede interpretar como la venganza de un pasado que se resiste al olvido. Sólo enfrentándolo puede ser superado.

\section{Medidas peligrosas}

El enfoque gubernamental es exclusivamente legal y parcial. Los hechos muestran que se carece de un plan para combatir el crimen, 
en cuya formulación debieran participar todas las instancias gubernamentales relacionadas con la seguridad pública, las organizaciones sociales y los expertos. Los esfuerzos de la policía sólo serán exitosos si están orientados por un plan y no por medidas legales aisladas.

La ineficacia de las leyes de emergencia está garantizada de antemano, porque su formulación no responde a un análisis serio del fenómeno, sino a una reacción visceral, en la cual el deseo por responder a la violencia con más violencia es evidente. Las leyes de emergencia crean la falsa impresión de que se hace mucho, siendo muy duro. Aparte de que contradicen tratados internacionales y a la Constitución. Las leyes propuestas recuerdan otra ley para garantizar el orden público, decretada durante la guerra, la cual, además de ser una aberración jurídica, no consiguió lo que pretendía y estimuló la violación de los derechos humanos.

Si las leyes se aplican conforme al espíritu de sus autores, cualquier sospechoso puede acabar en la cárcel. De hecho, se busca encarcelar a la mayoría de los delincuentes. Por eso se otorga mucha libertad a la policía y a los jueces. Pero esto agudizará aún más la degradante situación inhumana de las cárceles. El espíritu de las leyes no es bueno, porque responde más a la desesperación y la improvisación. Por lo tanto, sus resultados serán contrarios a la convivencia social y no conseguirán el objetivo buscado. Más aún, el peligro de la reaparición de la tortura y de los escuadrones de limpieza social es real.

Por lo general se piensa que la violencia es una realidad externa que afecta a las personas y los grupos. Convertida en objeto exterior, se llama delincuencia y a ella y sus representantes se les stribuyen todos los males y se adoptan políticas para contrarrestarlas, "tilizando los mismos recursos que los delincuentes. De esta manera se ignora la responsabilidad personal y social en la tolerancia y promoción de la violencia. Si el foco del problema se encuentra fuera, la solución inexorable pide su eliminación física, con la cárcel o el asesinato.

Pocas veces el tratamiento de la delincuencia considera la revisión de las actitudes individuales que estimulan la impunidad y la ineficiencia del aparato de seguridad y del sistema judicial, el control del tráfico de armas, una política sobre los modelos de conducta difundidos por los medios de comunicación social, en particular la televisión, retomar la investigación del Grupo Conjunto que vinculó los escuadrones de la muerte con el crimen organizado, crear alternativas a la mara para la juventud, que constituye la mayoría de la población salvadoreña.

La histeria generalizada pasa por alto que la raíz de la violencia, al menos parcialmente, se encuentra en la frustración de buena parte de 
la población, derivada de su lucha por la supervivencia, en una situación de pobreza e injusticia estructural, situación que se mantiene pese a los cambios políticos ocurridos a partir de 1992. Se pasa por alto que mientras no se ataquen estas condiciones, la delincuencia y la violencia seguirán socavando las relaciones sociales y debilitando las estructuras de la sociedad.

\section{La transición corre el peligro de desembocar en una guerra informal.}

En lugar de considerar el fenómeno en su complejidad, éste se simplifica, reduciéndolo a delincuencia común juvenil o callejera, se exalta la represión, se estimulan la paranoia y la intolerancia ante la sospecha y, sobre todo, se legitima nuevamente el uso de la fuerza por parte del Estado para controlar a la población, lo cual pone en peligro la frágil institucionalidad democrática del país.

Si estas tendencias hacia la descomposición social no se contrarrestan eficazmente, la transición corre el peligro de desembocar en una guerra informal. De hecho, ya existe una especie de guerra social, no de ejércitos formales, sino de grupos informales. Es una guerra nacional, pero difusa, cuyos combates son inorgánicos. Aunque carece de ideas y proyecto social, es igualmente devastadora y su final será mucho más difícil que el de la guerra pasada, precisamente por su carácter informal.

Lo más grave del planteamiento oficial no es tanto que pase por alto estos aspectos y emita leyes de excepción, sino que no quiera ver la complejidad del fenómeno de la violencia. La solución no está, pues, en responder con más violencia, sin negar que la sociedad deba contar con mecanismos de coacción, sino que hay que comenzar erradicando la impunidad y la corrupción, lo cual traslada la solución al plano político. Es decir, el aparato de seguridad y el sistema de justicia debieran funcionar sin otorgar privilegios a nadie $y$ mucho menos a los poderosos. Al contrario, la justicia debe enfatizar la protección a los más débiles. A mediano plazo, la solución es social y económica, sólo promoviendo cambios radicales se podrá avanzar hacia una convivencia pacífica.

Junta de Directores. 